\title{
Fulminant parvovirus B19 myocarditis after chemotherapy: full recovery after antiviral therapy with tenofovir
}

\author{
Tobias Koenig $^{1} \cdot$ Tibor Kempf $^{1} \cdot$ Heinz-Peter Schultheiss ${ }^{2} \cdot$ Markus Cornberg $^{3} \cdot$ Johann Bauersachs $^{1}$. \\ Andreas Schäfer ${ }^{1}$
}

Received: 1 July 2021 / Accepted: 15 October 2021 / Published online: 20 October 2021

(c) The Author(s) 2021

Sirs:

A 19-year-old female patient presented to the emergency department with fever, tachycardia, dyspnea, and abdominal pain. She was diagnosed with an ovarian germ cell tumor 1 month previously. Chemotherapy had been initiated including cisplatin, etoposide, and bleomycin 2 weeks before. Transthoracic echocardiography showed normal left ventricular (LV) and right ventricular function prior to chemotherapy.

On admission, physical examination and electrocardiogram did not show relevant pathologies. Heart rate was 120 beats per minute (sinus rhythm), blood pressure was $101 / 58 \mathrm{mmHg}$, and temperature was $38.5^{\circ} \mathrm{C}$. Laboratory analyses revealed markedly elevated $\mathrm{C}$-reactive protein $(302 \mathrm{mg} / \mathrm{L}$, reference value $<6 \mathrm{mg} / \mathrm{L})$ and procalcitonin $(9.6 \mu \mathrm{g} / \mathrm{L}$, reference value $<0.1 \mu \mathrm{g} / \mathrm{L})$, and severe leukocytopenia $(100 / \mu \mathrm{L}$, reference value 3600 to $10,500 / \mu \mathrm{L})$. A transthoracic echocardiogram showed severely impaired systolic LV function and LV dilatation, and preserved systolic right ventricular function (Supplemental Video 1). There was moderate to severe mitral regurgitation. Chest X-ray demonstrated pulmonary congestion and a left-sided pleural effusion.

The patient's status rapidly deteriorated and she developed severe cardiogenic shock (serum lactate $2.5 \mathrm{mmol} / \mathrm{L}$,

Tobias Koenig

koenig.tobias@mh-hannover.de

1 Department of Cardiology and Angiology, Hannover Medical School, Carl-Neuberg-Str. 1, 30625 Hannover, Germany

2 Institute for Cardiac Diagnostics and Therapy, IKDT GmbH, Berlin, Germany

3 Department of Gastroenterology, Hepatology and Endocrinology, Hannover Medical School, Hannover, Germany
LV end-diastolic pressure $21 \mathrm{mmHg}$ ) requiring highdose vasopressors and inotropes. NT-pro BNP level was 29,390 ng/L, hs-Troponin T level was $66 \mathrm{ng} / \mathrm{L}$. The patient was urgently transferred to the catheterization laboratory. Coronary angiography revealed normal coronary arteries. Endomyocardial biopsies (EMB) from the LV were obtained and an Impella CP micro-axial flow-pump (Abiomed, Danvers, Massachusetts, USA) was inserted for LV unloading [1].

The patient was intubated and mechanically ventilated due to progressive respiratory failure despite rapid stabilization of hemodynamics on mechanical support. Levosimendan was administered to gradually reduce vasopressors and inotropes. After $19 \mathrm{~h}$ on Impella support, inotropes were weaned and early intravenous heart failure treatment was started using the short-acting $\beta$-blocker landiolol due to its almost neutral effect on blood pressure. Antibiotic treatment was applied due to bacteremia with Escherichia coli and Streptococcus salivarius. High-dose corticosteroids were given for 3 consecutive days, but without significant clinical benefit.

Histologic, immunohistologic, molecular, and virological analyses of the EMBs (Fig. 1) were performed. Molecular diagnostics for common cardiotropic viruses were made by PCR testing $[2,3]$. In addition to diagnostics of B19V genomes, B19V viral activity was assessed [4]. Two quantitative PCR (qPCR) assays specifically amplifying the B19V non-structural (NS1) and capsid protein (VP1/2) sequences were applied to establish diagnosis of active viral infection. A viral load of $1926 \pm 1104$ copies per $\mu$ g genomic DNA was measured. Sequencing of a VP1/2 fragment could identify infection with B19V genotype 1. Detection of viral RNA as a sign of viral transcriptional activity was confirmed for both viral transcripts, the NS1 $(156 \pm 35$ transcripts per $\mu \mathrm{g}$ total RNA) and VP1/2 sequences ( $831 \pm 42$ transcripts per $\mu \mathrm{g}$ total RNA). Co-infection with other cardiotropic viruses and systemic virus infection were excluded. For the evaluation 

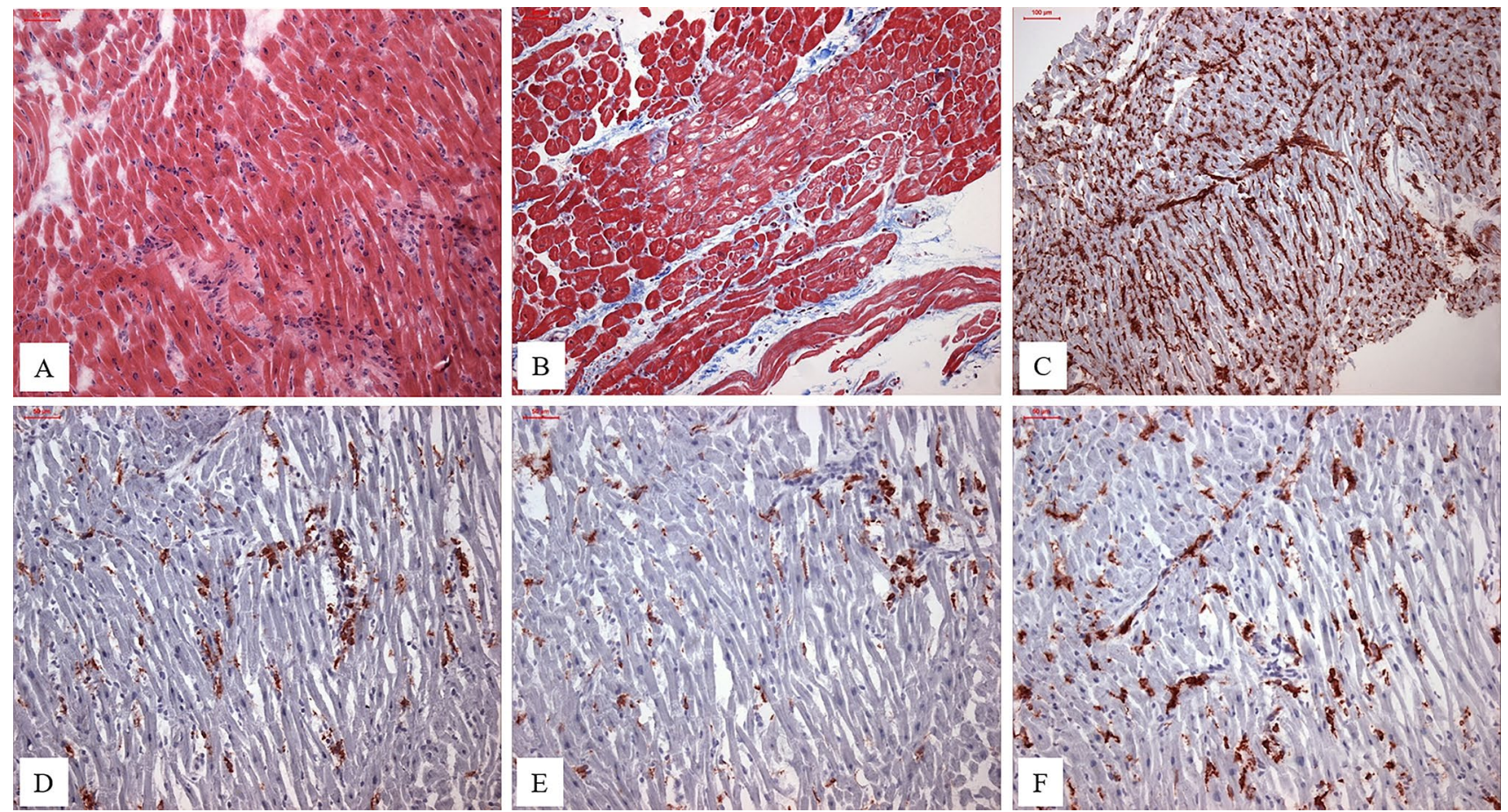

Fig. 1 A Increased inflammatory cells as signs of active and chronic inflammation in a B19V-positive patient with transcriptional activity. Note the variation of myocyte diameters. H\&E stain, bar $50 \mu \mathrm{m}$. B Increase of interstitial fibrosis (blue). PAS stain, bar $50 \mu \mathrm{m}$. C Immunohistochemical staining of increased Human Leukocyte Antigen-DR isotype-(HLA-DR) expression, bar $100 \mu \mathrm{m}$. D Immuno-

of morphological features and detection of myocarditis, four standard stains were used (Heidenhain's AZAN trichrome stain, haematoxylin and eosin stain, elastic Van Gieson stain, and periodic acid-Schiff stain) (Fig. 2). Immunohistochemistry was used to characterize inflammatory infiltration. Myocardial inflammation was present with 14.0 lymphocytes $/ \mathrm{mm}^{2}$. Macrophages $(\mathrm{CD} 1 \mathrm{~b}+/ \mathrm{Mac}-1+), \mathrm{CD} 45 \mathrm{R} 0 \mathrm{~T}$ histochemical staining of pronounced increased diffuse infiltration of CD3-positive T lymphocytes, bar $50 \mu \mathrm{m}$. E Immunohistochemical staining of increased infiltration of CD11a-positive lymphocytes, bar $50 \mu \mathrm{m}$. F Immunohistochemical staining of pronounced increased infiltration of CD11b/MAC-1-positive macrophages, bar $50 \mu \mathrm{m}$

Memory cells, and perforin-positive cytotoxic cells (CD3+) were analyzed and showed increased infiltrations.

Based on the clinical course, persistently reduced LV function and evidence of actively replicating B19V an antiviral therapy with tenofovir disoproxil (245 $\mathrm{mg}$ once daily) was initiated. Following step-wise reduction of pump-flow, the Impella pump was removed on day 8. Oral heart failure
Fig. 2 Cardiac MRI (4-chamber-view exemplarily) showing A no myocardial edema (T2-weighted edema images), and $\mathbf{B}$ no residual (T1-weighted) late gadolinium enhancement
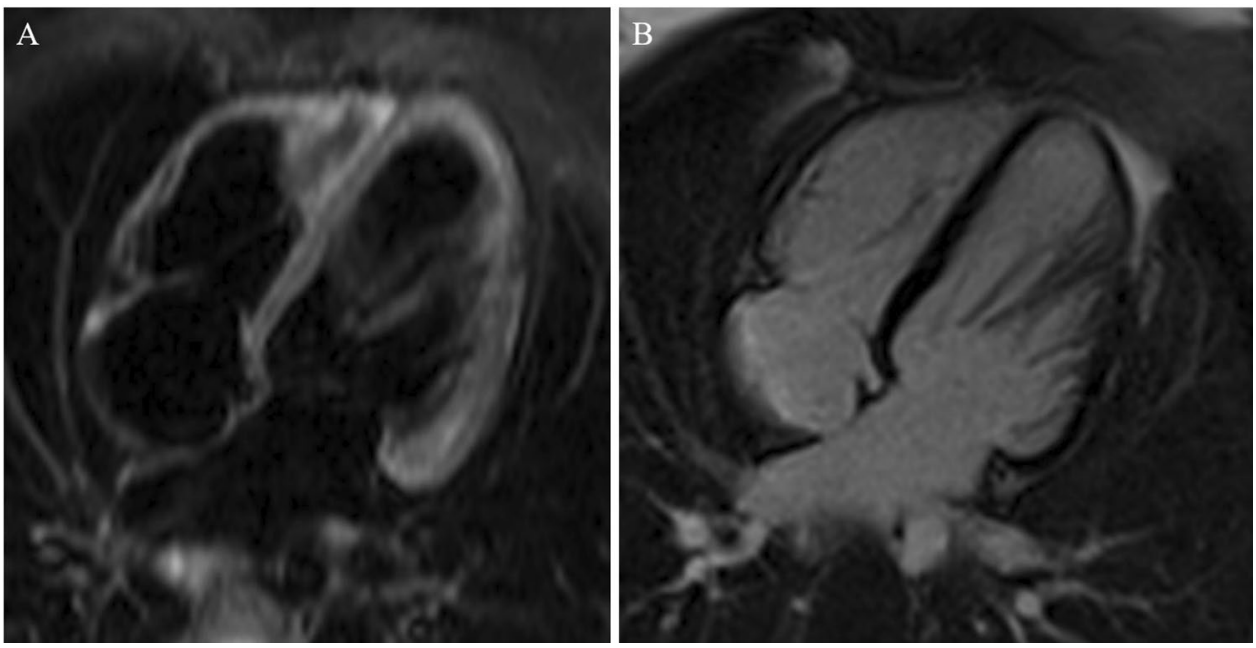
therapy was started including a beta-blocker, an angiotensin-converting enzyme inhibitor, and a mineralocorticoidreceptor antagonist. The patient remained in stable clinical condition. LV function steadily improved and was mildly reduced at discharge on day 17. On 3 month follow-up, LV function was completely normalized (Supplemental Video 2 ). There were no signs or symptoms of heart failure. No major adverse events occurred. NT-pro BNP level dropped to $167 \mathrm{ng} / \mathrm{L}$. On 4 month follow-up, cardiac magnetic resonance imaging demonstrated the absence of late gadolinium enhancement and myocardial edema (Fig. 2). Due to complete recovery and physiological MRI findings no additional EMB has been performed.

We hypothesize that the patient developed severe heart failure due to immunosuppression caused by chemotherapy and subsequent activation of $\mathrm{B} 19 \mathrm{~V}$ replication that ultimately led to active myocarditis. Expression of both viral transcripts (NS1 and VP1/2) indicates B19V transcriptional activity. In contrast to latent infection (solely DNA genomes), expression of B19V viral RNA in the myocardium has been demonstrated to be of clinical significance $[4,5]$. Treatment options of patients with acute lymphocytic myocarditis with LV dysfunction are poorly studied. Particularly, data on patients with acute B19V myocarditis are scarce. Treatment concepts include interferon-beta, immunoglobulins and antiviral therapy [6-8]. Van Linthout and colleagues previously reported 4 patients suffering from biopsy-proven chronic lymphocytic myocarditis and human B19V transcriptional activity who were treated with telbivudine (600 mg once daily for 6 months) that was initially approved to treat chronic hepatitis B virus infection [9]. After 6 months, endomyocardial biopsies showed decreased VP1/V2-mRNA levels and CD3 cells in all patients. This was associated with an improvement of LV function and New York Heart Association (NYHA) functional class. Consequently, the decision was made to initiate antiviral therapy. However, telbivudine is no longer available in Germany and an alternative was required. Telbivudine is a nucleoside analogue that inhibits viral DNA polymerase (reverse transcriptase). Additional pleiotropic immunomodulatory and anti-inflammatory effects have been shown [10]. Tenofovir also acts via nucleotide analogue reverse transcriptase inhibition and is approved for the treatment of HIV infection and chronic hepatitis B, but treatment of active B19V myocarditis with tenofovir has not yet been described. Because of similar pharmacological properties of telbivudine and tenofovir in the absence of therapeutic alternatives, we selected tenofovir disoproxil ( $245 \mathrm{mg}$ once daily for 6 months) in combination with guideline-recommended heart failure therapy and temporary mechanical circulatory support $[7,11]$.

Acute viral myocarditis with cardiogenic shock early after chemotherapy is a rare and life-threatening entity. EMB can unveil the underlying pathology and guide diagnosis and specific therapy. Tenofovir disoproxil on top of guidelinerecommended heart failure therapy demonstrated a safe and effective specific treatment option in this case of B19Vinduced acute myocarditis.

Supplementary Information The online version contains supplementary material available at https://doi.org/10.1007/s00392-021-01955-3.

Funding Open Access funding enabled and organized by Projekt DEAL.

Data availability All data and material are available and can be provided if requested.

Code availability Not applicable.

\section{Declarations}

Conflict of interest The authors have no relationships relevant to the contents of this paper to disclose.

Open Access This article is licensed under a Creative Commons Attribution 4.0 International License, which permits use, sharing, adaptation, distribution and reproduction in any medium or format, as long as you give appropriate credit to the original author(s) and the source, provide a link to the Creative Commons licence, and indicate if changes were made. The images or other third party material in this article are included in the article's Creative Commons licence, unless indicated otherwise in a credit line to the material. If material is not included in the article's Creative Commons licence and your intended use is not permitted by statutory regulation or exceeds the permitted use, you will need to obtain permission directly from the copyright holder. To view a copy of this licence, visit http://creativecommons.org/licenses/by/4.0/.

\section{References}

1. Schäfer A, Werner N, Westenfeld R, Moller JE, Schulze PC, Karatolios K et al (2019) Clinical scenarios for use of transvalvular microaxial pumps in acute heart failure and cardiogenic shock-a European experienced users working group opinion. Int J Cardiol 291:96-104. https://doi.org/10.1016/j.ijcard.2019.05.044

2. Kühl U, Pauschinger M, Noutsias M, Seeberg B, Bock T, Lassner D et al (2005) High prevalence of viral genomes and multiple viral infections in the myocardium of adults with "idiopathic" left ventricular dysfunction. Circulation 111(7):887-893. https://doi. org/10.1161/01.CIR.0000155616.07901.35

3. Escher F, Pietsch H, Aleshcheva G, Bock T, Baumeier C, Elsaesser A et al (2020) Detection of viral SARS-CoV-2 genomes and histopathological changes in endomyocardial biopsies. ESC Heart Fail 7(5):2440-2447. https://doi.org/10.1002/ehf2.12805

4. Pietsch H, Escher F, Aleshcheva G, Lassner D, Bock CT, Schultheiss HP (2020) Detection of parvovirus mRNAs as markers for viral activity in endomyocardial biopsy-based diagnosis of patients with unexplained heart failure. Sci Rep 10(1):22354. https://doi.org/10.1038/s41598-020-78597-4

5. Kühl U, Lassner D, Dorner A, Rohde M, Escher F, Seeberg B et al (2013) A distinct subgroup of cardiomyopathy patients characterized by transcriptionally active cardiotropic erythrovirus and altered cardiac gene expression. Basic Res Cardiol 108(5):372. https://doi.org/10.1007/s00395-013-0372-y 
6. Caforio AL, Pankuweit S, Arbustini E, Basso C, Gimeno-Blanes J, Felix SB et al (2013) Current state of knowledge on aetiology, diagnosis, management, and therapy of myocarditis: a position statement of the European Society of Cardiology Working Group on Myocardial and Pericardial Diseases. Eur Heart J 34(33):263648a-48d. https://doi.org/10.1093/eurheartj/eht210

7. Schultheiss HP, Bock T, Pietsch H, Aleshcheva G, Baumeier C, Fruhwald F et al (2021) Nucleoside analogue reverse transcriptase inhibitors improve clinical outcome in transcriptional active human parvovirus B19-positive patients. J Clin Med. https://doi. org/10.3390/jcm10091928

8. Schultheiss HP, Piper C, Sowade O, Waagstein F, Kapp JF, Wegscheider K et al (2016) Betaferon in chronic viral cardiomyopathy (BICC) trial: effects of interferon-beta treatment in patients with chronic viral cardiomyopathy. Clin Res Cardiol 105(9):763-773. https://doi.org/10.1007/s00392-016-0986-9
9. Van Linthout S, Elsanhoury A, Klein O, Sosnowski M, Miteva $\mathrm{K}$, Lassner D et al (2018) Telbivudine in chronic lymphocytic myocarditis and human parvovirus B19 transcriptional activity. ESC Heart Fail 5(5):818-829. https://doi.org/10.1002/ehf2.12341

10. Wang GQ, Ding YP, Dong YH (2013) Telbivudine treatment is associated with high hepatitis $\mathrm{B}$ e antigen seroconversion and immune modulatory effects in chronic hepatitis B patients. J Viral Hepat 20(Suppl 1):9-17. https://doi.org/10.1111/jvh.12059

11. Tschöpe C, Van Linthout S, Klein O, Mairinger T, Krackhardt F, Potapov EV et al (2019) Mechanical unloading by fulminant myocarditis: LV-IMPELLA, ECMELLA, BI-PELLA, and PROPELLA concepts. J Cardiovasc Transl Res 12(2):116-123. https:// doi.org/10.1007/s12265-018-9820-2 